\title{
Redes sociais na produção científica em administração pública da saúde no Brasil
}

\begin{abstract}
Ana Cristina Vidal Allegretti ${ }^{1}$
Simone Tetu Moysés'

Renata lani Werneck ${ }^{1}$

Carlos Olavo Quandt ${ }^{2}$

Samuel Jorge Moysés ${ }^{1}$

${ }_{1}^{1}$ Pontifícia Universidade Católica do Paraná / Programa de Pós-Graduação em Odontologia — Saúde Coletiva, Curitiba / PR — Brasil

2 Pontifícia Universidade Católica do Paraná / Programa de Pós-Graduação em Administração, Curitiba / PR — Brasil
\end{abstract}

\begin{abstract}
A reforma administrativa no Brasil, iniciada com a Constituição de 1988, permitiu a efetivação de políticas públicas descentralizadas, incluindo a municipalização do setor saúde e participação popular. Objetivando apreender como essas mudanças democráticas ecoaram na literatura internacional, o artigo analisou a produção científica da administração pública da saúde no Brasil, adotando o estudo de redes sociais. A pesquisa foi feita na base do Web of Science, utilizando termos relacionados com administração, delimitada por "Brazil" e "health", e softwares auxiliares BibExcel e Ucinet. A rede de publicações da administração se mostrou coesa, com práticas de democracia deliberativa e participação social. Ao incluir o termo "saúde", houve maior variação de temas, com destaque para a Reforma Sanitária e descentralização do Sistema Único de Saúde, de forma crítica e reflexiva, e notada ausência do controle social.
\end{abstract}

Palavras-chave: administração pública; saúde; análise de redes sociais.

\section{Redes sociales en la producción científica en administración pública de la salud en Brasil}

La reforma administrativa en Brasil, iniciada con la Constitución de 1988, permitió la efectuación de políticas públicas descentralizadas, tales como la municipalización del área de salud previendo mayor abertura para la participación popular. Objetivando aprehender como la efectuación de esos cambios tuvo eco en la literatura internacional, el presente artículo analizó la producción científica a respecto de la administración pública de la salud en Brasil, adoptando el estudio de redes sociales. La investigación se realizó con base en la Web of Science, utilizando los términos relacionados a la administración, delimitada por "Brazil" y "health", y los programas BibExcel e Ucinet. La red de publicaciones de la administración se mostró coherente, conteniendo prácticas de democracia deliberativa y participación social. Al incluir el término "salud", hubo una mayor variación de temas, con destaque para la Reforma Sanitaria Brasileña y la descentralización del Sistema Único de Salud, con enfoque más crítico y reflexivo, e importante laguna relativa al control social.

Palabras clave: administración pública; salud; análisis de las redes sociales.

\section{Social Networks in the scientific production on public health administration in Brazil}

The Brazilian administrative reform was included in the 1988 Constitution, and it has promoted decentralized policies, including the municipalization of health and popular participation. The objective of this article is to understand how the implementation of these democratic changes were studied in the international literature. The scientific production on Brazilian public health administration was analyzed by studying social networks. The search was conducted in the Web of Science database, using administration terms, delimited by "Brazil" and "health," and using BibExcel and Ucinet software. The network of publications in administration was cohesive, containing practices of deliberative democracy and social participation. By including the term "health," more variations were found, particularly on the Brazilian Health Reform and on the decentralization of the National Health System, with a more critical and reflexive focus, albeit with a clear gap on social accountability.

Keywords: public administration; health; social network analysis. 


\section{INTRODUÇÃO}

O campo de interesse do presente artigo de análise bibliométrica se dirige à ciência da administração pública (particularmente em saúde). A problematização de indicadores bibliométricos é relevante, especialmente pela abordagem metodológica focalizada neste trabalho. Parte-se do pressuposto teórico de que autores formam redes sociais, analogamente ao conceito corrente de um grupo de contatos sociais ou laços entre indivíduos em que há interação entre eles. A análise de redes sociais em bibliometria é uma ferramenta metodológica que permite formalizar graficamente, de forma quantitativa, conceitos abstraídos a partir de propriedades e processos característicos da realidade social (Souza e Quandt, 2008). Isso torna possível identificar agrupamentos de autores, suas relações e conexões, padrões e alterações ocorridas em um determinado período de tempo. A colaboração científica pode ser medida a partir dos vínculos entre pesquisadores, instituições ou países que compartilham autoria em trabalhos acadêmicos. Assim, a análise de redes sociais apresenta vantagens em comparação com metodologias tradicionais que avaliam apenas atributos individuais de autores (Scott, 2000).

O estudo de redes sociais tem como base a sociologia e a teoria das organizações. Permite o entendimento de como os laços são estabelecidos entre indivíduos em um contexto dado, definindo padrões de relação e dinâmica de interação, e visualizando as relações sociais circunscritas entre instituições. Os atores (autores, no presente caso) em uma rede possuem conexões interdependentes, com influências diretas e indiretas, gerando oportunidades ou restrições em termos de protagonismo de ação individual e colaborativa (Ullrich, Oliveira e Scheffer, 2012). Isso permite conhecer e discutir, entre outros aspectos, a contribuição e a influência de autores em um dado campo temático, bem como suas eventuais conexões, as instituições a que estão filiados, os temas priorizados, os enfoques teóricos e as metodologias adotadas.

Conforme enfatizado no início, o campo temático de interesse aqui é a administração pública e a administração da saúde. O campo trata, entre outras questões, do estudo das instituições que deveriam ter como objetivos centrais a gestão responsável e transparente dos interesses públicos e a satisfação das necessidades coletivas. Tais objetivos são alcançáveis a partir da formulação e implementação de políticas públicas democraticamente consensualizadas e do uso efetivo e eficiente dos recursos disponíveis (Carvalho, 2013). Com base nessa premissa, a "ação de governar" é encampada como um "território" histórico, multidisciplinar, prenhe de interesses, disputas e conflitos. Por esse território transitam muitas escolas ou correntes de pensamento que buscam descrever ou interpretar seus pressupostos ontológicos, seus encaminhamentos teleológicos, seus nexos temporais e culturais (Marques e Faria, 2013).

É, na verdade, um campo de ação humana que possui “personalidade múltipla”, pois se origina em diferentes lugares e tem destinos diversos, sendo atravessado por relações de poder (Pollitt, 2010). As forças políticas que podem conferir racionalidade e direcionalidade à administração pública têm seu centro de gravidade nos aparatos de Estado e seus desdobramentos tentaculares - o setor público em sua relação com a sociedade - e não somente a partir de seus fundamentos internos: modelos operativos, teorias ou métodos de organização.

Desde pelo menos a década de 1970, importantes transformações no campo temático das políticas públicas têm ocorrido, afetando diretamente a ação de governar em distintas nações, alterando estruturas estatais e o processo governamental em si mesmo, como a relação entre o Estado e a sociedade civil (Hochman, Arretche e Marques, 2008). As políticas públicas podem ser entendidas, em 
sociedades ocidentais modernas, como a tradução dos propósitos e plataformas eleitorais de governos democráticos em programas e ações, devendo oferecer resultados concretos para a vida das pessoas. Buscam, simultaneamente, "colocar o governo em ação", bem como propor alterações no curso dessas ações, quando necessário (Souza, 2006). As transformações, em décadas subsequentes, atingiram de forma diferente os países e seus respectivos segmentos sociais, em momentos e formas também distintos, todavia a discussão tem ocorrido mais no contexto do novo "gerencialismo" que penetra a esfera pública (Peters, 2008). A partir dos anos 1980, vai se tornando perceptível uma mudança de abordagem de alguns estudos sobre a administração pública, com uma linguagem "gerencial" perpassando vários textos, refletindo a introdução do racionalismo econômico que passou a caracterizar o desenho organizativo dos serviços públicos (Carneiro e Menicucci, 2011).

No contexto brasileiro, a reforma administrativa do Estado teve início com o fim do período militar. Admite-se que a Constituição Federal de 1988 trouxe elementos importantes para a nação: a democratização do Estado, com o fortalecimento do controle externo pelo Ministério Público; a descentralização de várias políticas, incluindo a de saúde, que gerou oportunidades de maior participação de atores do nível locorregional; e iniciativas de profissionalização da burocracia estatal, consolidada por concurso público, que estaria progressivamente submetida ao princípio da seleção meritocrática e universal em uma perspectiva neoweberiana (Abrúcio, 2007). O governo do presidente Fernando Henrique Cardoso (FHC), sob inspiração de reformas administrativas ocorridas também na Europa, optou pela implementação da chamada "nova gestão pública" (New Public Management) - um modelo gerencial conformado para a pretendida reconstrução do Estado (Bresser-Pereira, 1997). A proposta da era FHC defendia mudanças institucionais relativas à flexibilização da força de trabalho com vínculo público e criação de espaços públicos não estatais.

A sucessão política representada pelo Partido dos Trabalhadores, a partir de 2003, suscitou uma expectativa pós-eleitoral que supostamente seria contrária às ideias do modelo gerencial precedente. No entanto, é também correto analisar o período do governo encetado por Luiz Inácio Lula da Silva como um caminho marcado por embates e contradições, resultando na adoção (muitas vezes tensionada e difusa) da "gestão por resultados", ao invés da rejeição pura e simples das ideias do período governamental anterior. A mudança se deu mais de forma incremental e principalmente nos processos, em vez de alterar a lógica organizacional como um todo (Abrúcio, 2011). As reformas propostas na era Lula incluíam um conjunto de ações que vocalizavam a retórica de um Estado promotor de inclusão social, em que o governo federal acentuaria seu papel de planejador e orientador, tendo como intermediadores os estados federativos, e como executores locais os municípios (Klering, Porsse e Guadagnin, 2010). A partir do escrutínio dos Planos Plurianuais (PPA), dos governos Lula e Dilma, é possível perceber uma concepção muito particular do conceito de "modernização" do modelo de administração, por meio da revalorização do planejamento e da força mobilizadora estatal, como uma estratégia de reabilitar as atividades do Estado e melhorar a prestação de serviços públicos. Dessa forma, os canais de participação formal e o planejamento governamental foram valorizados como meios fundamentais para viabilizar um projeto alternativo de poder (Lima e Papi, 2015).

No campo da saúde, o movimento denominado de Reforma Sanitária Brasileira ganhou ímpeto simultaneamente ao processo de redemocratização do país, sobretudo ao longo dos anos 1980. A Constituição de 1988 incorporou a saúde como um direito do cidadão e dever do Estado, instituindo o Sistema Único de Saúde (SUS), representando um movimento amplo de subjetivação, constitucionalização e institucionalização que rompe com o modelo anterior de concepção de Estado 
e de cidadania (Fleury, 2009). Estabeleceram-se, assim, as bases para um novo modelo de gestão da saúde, correlato à administração pública deliberativa (Paim et al., 2011).

A Lei no 8.080/1990, que regulamenta o SUS, comporta dimensões relacionadas com promoção, proteção e recuperação da saúde, as quais sistematizam o desejado modelo de atenção à saúde, que deveria se estruturar sob os princípios doutrinários da universalidade, integralidade e equidade; e sob as diretrizes organizativas da descentralização com comando único, regionalização e hierarquização dos serviços, e participação comunitária (Brasil, 1990).

Os postulados do SUS colocaram em evidência uma lógica político-organizativa e administrativa contrária às práticas até então vigentes no campo da saúde, que eram centralizadoras e com forte influência dos prestadores privados de serviços (Escorel, 2012; Mendes, 2013). Representaram um grande desafio para mudanças de ordem técnica, administrativa, política e cultural, as quais ainda não se completaram, sendo parte de uma ampla agenda social inconclusa (Alonso, Hedler e Castilho, 2010; Barros, Piola e Vianna, 1996).

O bom funcionamento (que implica boa gestão) do SUS constitui obrigação legal há mais de 25 anos; ainda que tenha sua origem no movimento da reforma sanitária, por meio da luta de uma diversificada militância, sua implementação vem sendo marcada por constantes obstáculos. Há problemas relacionados com o subfinanciamento federal, agravado por renúncias fiscais e por subsídios federais ao mercado de planos privados de saúde; resistência à reforma da estrutura administrativa estatal na prestação de serviços; e parcerias público-privadas ainda imersas em disputas de interesses pouco republicanos (Santos, 2013b).

Por outro lado, há avanços consideráveis na conceituação internacional de saúde, considerada pessoal e coletivamente um bem imaterial indispensável para a vida das pessoas e um recurso imprescindível para a reprodução social. Os serviços de saúde, por sua vez, têm características que geram exigências específicas em relação à organização e à gestão. São estruturas complexas e diversificadas (Tanaka e Tamaki, 2012), com diferentes aportes e necessidades, envolvendo variáveis biopsicossociais, serviços definidos por questões sociais, seja pela determinação ou representatividade da saúde/doença, pelo tipo de problema (agudo/crônico), entre outros (Dussalt, 1992).

A administração pública da saúde, mesmo com as tentativas de reformas, entre elas a de 1998, não conseguiu alcançar a agilidade e a resolutividade necessárias para dar efetividade aos direitos sociais tão longamente postergados. De fato, perde-se num cipoal de normas, regulamentos e controles do gestor público, sem, contudo, ser capaz de evitar a corrupção endêmica e garantir melhor qualidade sistêmica, com desempenho compatível aos anseios da sociedade brasileira que clama por serviços públicos de qualidade (Santos, 2013a).

Desse modo, para melhor compreender o contexto da efetivação das diretrizes constitucionais do sistema público de saúde no Brasil é necessário, além de reconhecer o saber acumulado a respeito do tema ao longo do tempo, também identificar pessoas, publicações e instituições que fomentam sua discussão e formação de opiniões. Ademais, identificar se os avanços e problemas próprios da administração pública, tratando-se de um sistema de saúde com a envergadura continental do SUS, ecoam nos fóruns científicos internacionais, particularmente pela via das publicações especializadas. Em termos de contribuição acadêmica, o presente estudo não busca dar respostas definitivas ou fazer uma revisão teórica abrangente, mas "mapear" redes sociais de autores que se conectam para produzir o conhecimento da administração pública e da administração da saúde, em termos de concepções elencadas e ações concretamente adotadas. 
Assim, o presente artigo se propõe a cartografar a produção científica a respeito da administração pública e da saúde no Brasil, com o objetivo de avaliar as possíveis influências de autores e publicações, por meio de um estudo de natureza bibliométrica com foco na análise da eventual constituição de redes sociais de autores.

\section{MÉTODO}

Um detalhamento metodológico sobre as ferramentas utilizadas para o presente estudo bibliográfico será útil. Os dados bibliográficos são baixados da Web of Science e migrados para o aplicativo BibExcel, que reconhece nessa base os campos de cada registro bibliográfico recuperado (delimitadores e tags, para AUTOR, COAUTOR, TÍTULO, entre outros). Ele faz isto no formato de texto simples e os dados são reestruturados pelo aplicativo em formato DIALOG, mais especificamente no formato do Science Citation Index ${ }^{\circledR}$, da Web of Science. Desse modo, dados de campos bibliográficos são transformados em campos unívocos de metadados. Na sequência, é gerada uma sociomatriz de redes em que algoritmos controlam, por exemplo, duplicações indesejáveis de campos bibliográficos. O menu "Analyze" presente no aplicativo permite funções analíticas especializadas sobre redes autorais e citações, acoplamentos bibliográficos e coocorrências de pares de citações, ou ainda conjunções de palavras usadas na indexação do material bibliográfico. Permite, ainda, o uso do algoritmo que possibilita a clusterização de campos bibliográficos selecionados, vetores ou partições de citações (referências mais citadas ou agregações temáticas), ou a construção de matrizes simétricas quadradas, com a visualização de mapas de redes e seu nível de coesão (conectividade, densidade, centralidade e grau de vizinhança). O BibExcel tem uma interface que permite fácil interação com o aplicativo Pajek ou Ucinet, que produzem as visualizações de redes, em formato gráfico; e Excel, que permite trabalhar em planilhas de dados (Persson, Danell e Schneider, 2009).

Para esta pesquisa foram realizadas as seguintes etapas:

1. Pesquisa na Web of Science, com busca realizada no período de 20 a 25 de junho de 2015, cobrindo toda a literatura indexada nessa base relativamente aos termos de busca. No primeiro campo foram inseridos os termos "administration", "management", "governance", "decentralization", acrescidos das expressões "public", "new public management", "public policy”. A pesquisa então foi delimitada pelos termos "Brazil ${ }^{\star *}$ e "health*", os quais geraram dois conjuntos de publicações: o primeiro associado à administração pública no Brasil (PUBLICAÇÕES_ADMINISTRAÇÃO_BRASIL $\rightarrow$ PAB) e um subgrupo desse relacionado com a saúde (PUBLICAÇÕES_ADMINISTRAÇÃO_SAÚDE_ BRASIL $\rightarrow$ PASB);

a. Descritores: foram selecionados a partir de consulta ao MeSH e Descritores em Ciências da Saúde (DeCS) (http://decs.bvs.br/), utilizando as expressões booleanas "AND" e "OR" e campo de busca "Tópico"

b. Tempo estipulado: Todos os anos

c. Índices: SCI-EXPANDED, SSCI, A\&HCI, CPCI-S, CPCI-SSH

2. Obtenção das tabelas da base de dados Web of Science para análise descritiva/bibliométrica;

3. Limpeza e procedimentos de consistência dos dados bibliográficos, utilizando o software BibExcel, até a geração de uma sociomatriz para análise (Persson, Danell e Schneider, 2009). O software possibilita isolar uma variável ou combinação destas a partir da delimitação dos campos dos registros 
bibliográficos. Depois de isolados, vários procedimentos específicos são necessários para gerar a sociomatriz ou matriz de coautoria (Ruas e Pereira, 2014);

4. Geração dos gráficos de rede dos sistemas sociais relacionais para evidenciar os padrões de relacionamento entre os atores (nós), com o auxílio do software Ucinet (Borgatti, Everett e Freman, 2002);

5. Análise das características e propriedades das redes: conectividade, densidade, centralidade e grau de vizinhança (Scott, 2000; Soares, 2012);

6. Verificação de autores/publicações mais relevantes, a partir das características das redes.

\section{RESULTADOS E DISCUSSÃO}

O processamento bibliográfico resultou em dois conjuntos de referências (autores, temas): $\mathrm{PAB}$, com 490 itens, e Pasb, com 205 itens, apresentadas na figura 1. Com relação à distribuição das publicações no tempo, observa-se que houve um crescimento expressivo de publicações, principalmente a partir de 2007 (figuras 2 e 3). O aumento do número de pós-graduações no Brasil nos últimos 10 anos pode explicar o aumento do número de publicações, uma vez que um dos critérios para a avaliação dos programas institucionalizados é o número dos artigos publicados por ano (Falavigna et al., 2012).

FIGURA 1 DESCRITORES E REFINAMENTOS DA PESQUISA, COM RESPECTIVOS NÚMEROS DE ITENS, 2015

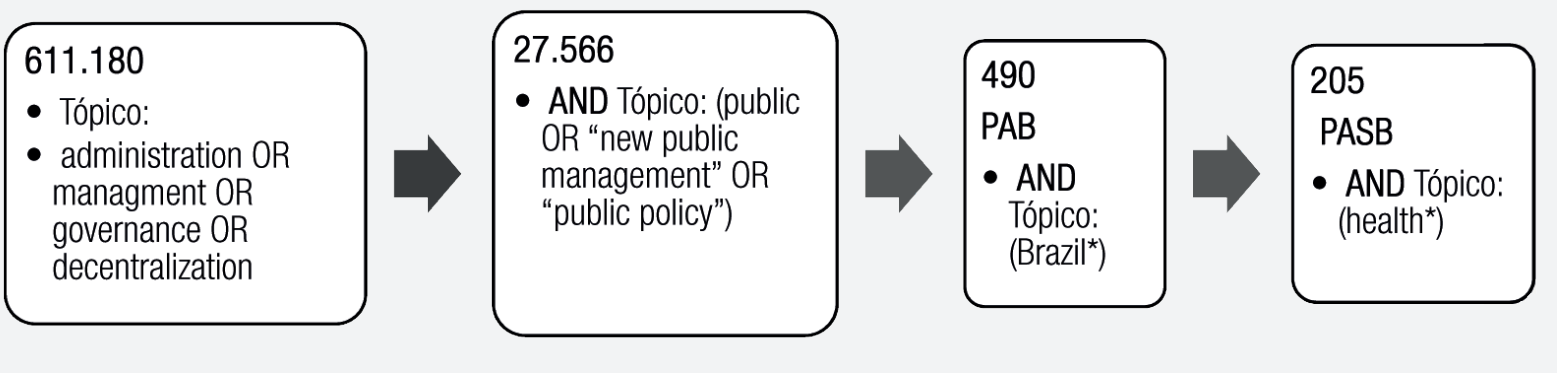

Fonte: Dados da pesquisa (2015).

De fato, a maior parte das publicações foi em formato de artigos originais (PAB - 83,53\% e Pasb $-89,75 \%$ ); as outras modalidades foram: revisões, editoriais, livros e anais de congressos. Quanto ao idioma, o inglês foi encontrado em $68,7 \%$ das publicações no conjunto PAB, seguido do português $(24,4 \%)$ e as demais línguas, espanhol e francês, que somaram $6,1 \%$. No conjunto Pasb a distribuição foi semelhante, com as seguintes frequências: $55,6 \%$ inglês, $40 \%$ português e $4,3 \%$ espanhol. A questão de o idioma inglês ter sido predominante tem relação com a dominância dessa língua na Web of Science e com orientações recentes, tais como da SciELo, que tem indicado percentuais mínimos de publicações na língua inglesa às editoras de periódicos científicos nacionais (Scielo, 2014).

Em relação às instituições às quais os autores são filiados, a Fundação Oswaldo Cruz e a Universidade de São Paulo foram as que mais geraram publicações nos dois conjuntos: PAB (17,9\%) e Pasb $(31,2 \%)$. Entre as 25 primeiras organizações, no conjunto PAB, sete são estrangeiras e 18 brasileiras; no conjunto Pasb são cinco organizações estrangeiras e 20 brasileiras. Nos dois grupos, entre as 
instituições nacionais, há apenas uma instituição privada para cada grupo; as demais são públicas. Essa informação pode ser sugestiva de que as instituições (ou os autores) estão buscando expandir o horizonte de internacionalização, com parcerias estrangeiras, além dos tradicionais intercâmbios de formação pós-graduada.

\section{FIGURA 2 ITENS PUBLICADOS POR ANO PAB, 2015}

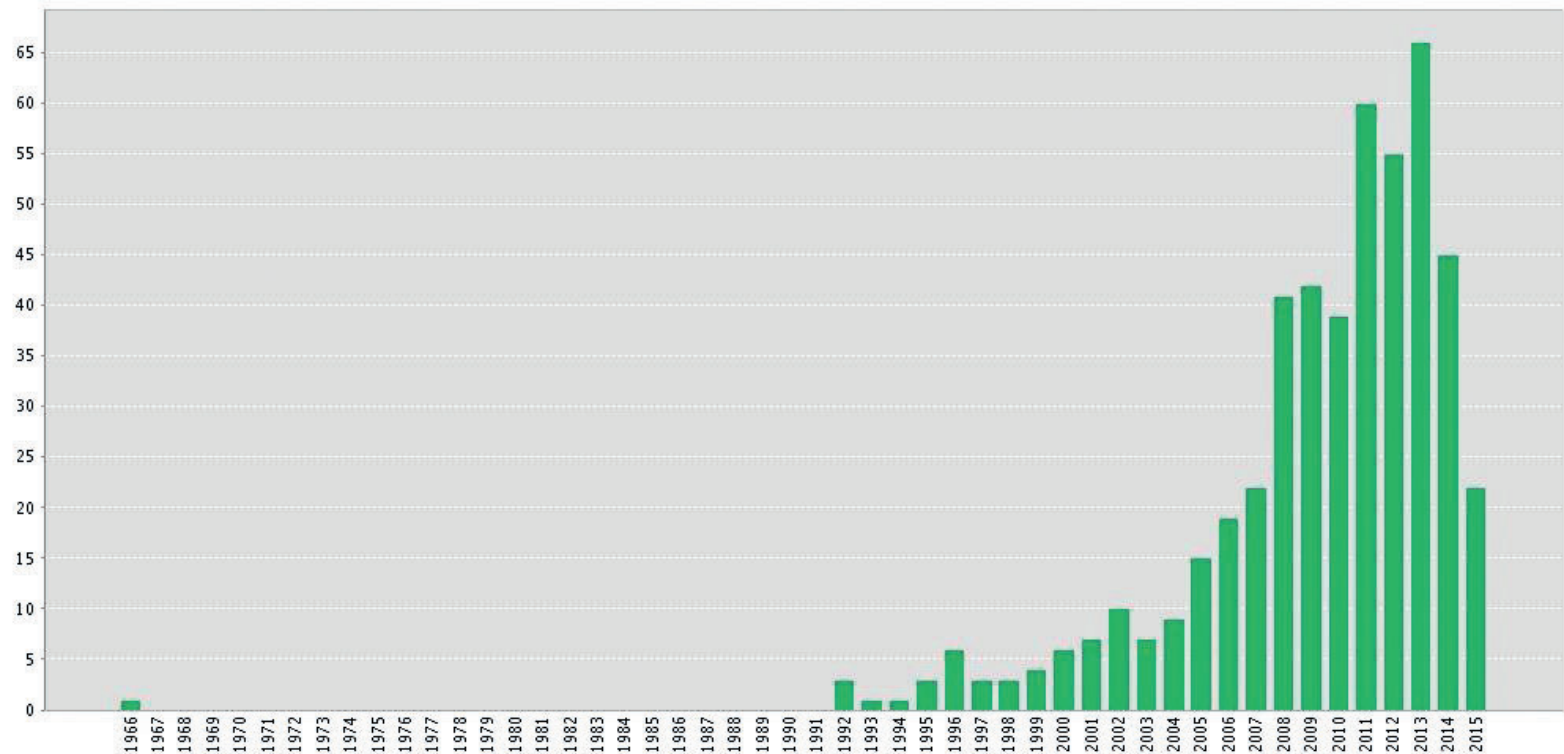

Fonte: Pesquisa Web of Science (2015).

\section{FIGURA 3 ITENS PUBLICADOS POR ANO PASB, 2015}

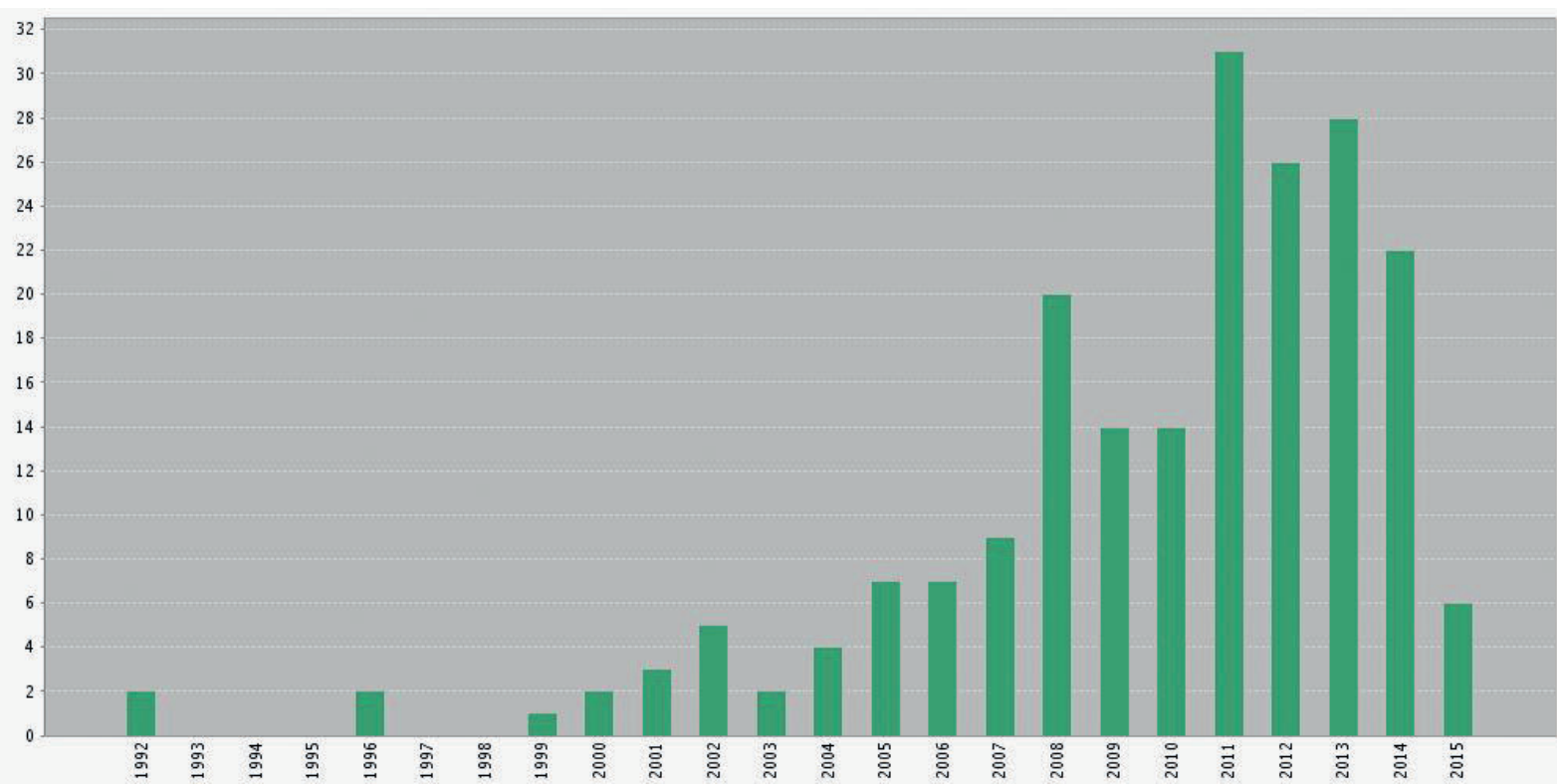

Fonte: Pesquisa Web of Science (2015). 
Categorizando as 25 primeiras instituições, de acordo com a localização geográfica e excluindo as estrangeiras, sua distribuição conforme região do Brasil é mostrada no gráfico 1. A Região Sudeste detém a maior parte das publicações nos dois grupos (mais de dois terços), e a segunda posição é ocupada pela Região Sul (no grupo PAB) e Região Nordeste (no grupo Pasb), seguidas da Região Centro-Oeste; e ausência de publicações da Região Norte. Em outra pesquisa foi identificado que os estados de São Paulo, Rio Grande do Sul e Rio de Janeiro têm razão de bolsistas CNPq por milhão de habitantes acima da média nacional (Martelli Junior et al., 2010), o que pode contribuir no esclarecimento dessas distribuições.

\section{GRÁFICO 1 DISTRIBUIÇÃO DAS INSTITUIÇÕES NOS CONJUNTOS PAB E PASB, CONFORME REGIÃO BRASILEIRA, 2015}

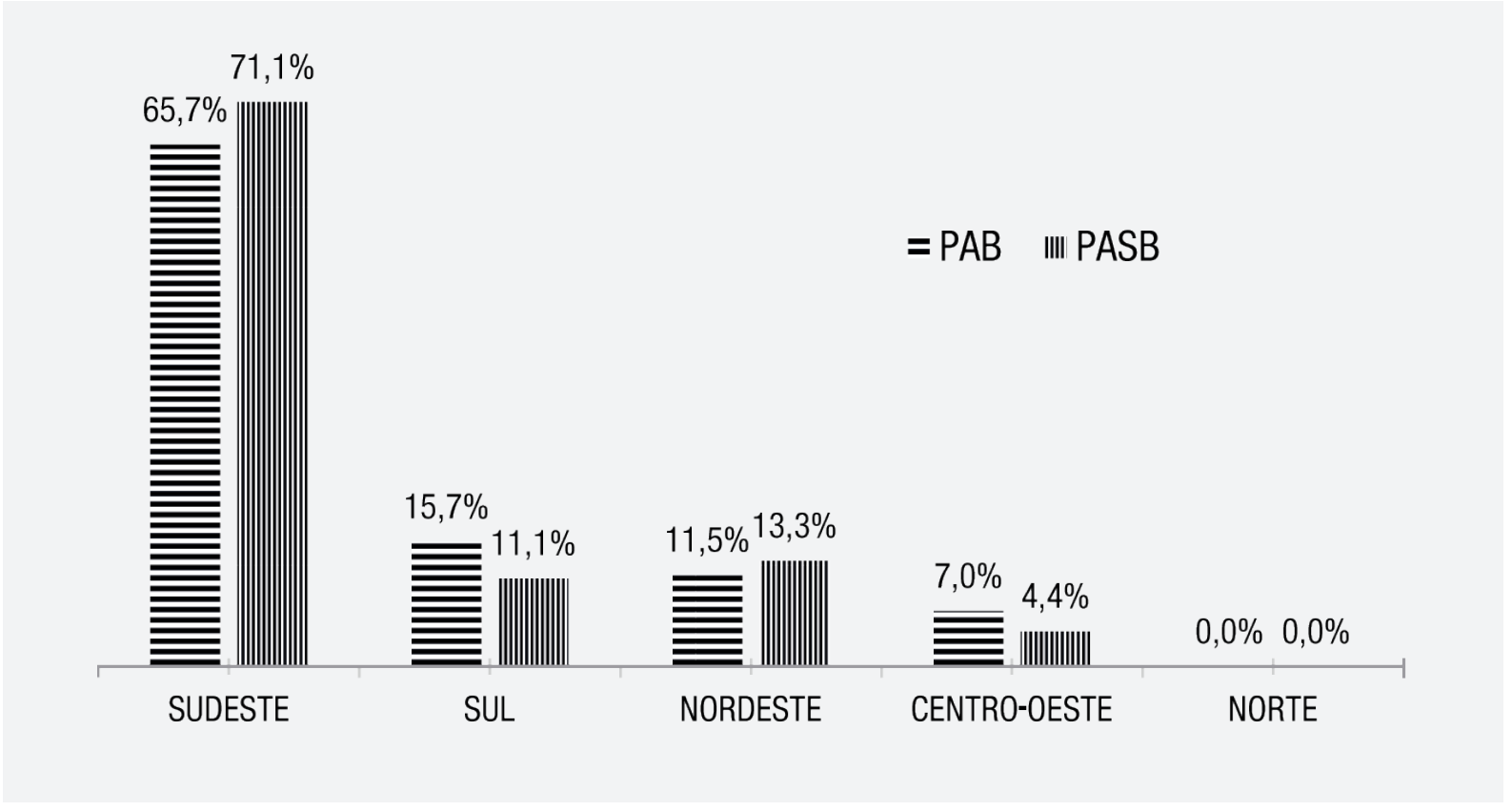

Fonte: Dados da pesquisa (2015).

Após a aplicação das ferramentas descritas em métodos, descortinaram-se duas redes, PAB e Pasb, formadas por 29 e 46 nós, respectivamente (figuras 4 e 6).

O quadro 1 exibe detalhes comparativos das duas redes, conforme suas características, que se apresentam conectadas e recíprocas. Observa-se que o algoritmo gerou um "cut point" na rede PAB - que é identificado pelo autor "Hunter 2007", ${ }^{1}$ mas sua presença não representa grande fragilidade para a rede, pois esse autor faz a comunicação entre todo o conjunto de nós com apenas outro autor que é "Arretche 2000".

${ }^{1}$ Sobrenome de autores que aparecem na seção de Resultados entre aspas não seguem as normas ABNT, pois são tratados como "objetos" ou "itens" de metadados obtidos com os algoritmos das ferramentas de busca. 
Com referência à proporção de ligações autorais presentes, em relação ao total possível, a rede PAB é mais densa do que a rede Pasb, o que pode significar grande coesão entre as publicações/ autores na primeira rede, em que há, inclusive, um subconjunto de 17 nós com $k$ core mínimo de 12 (grande interação entre eles). Por outro lado, pode-se argumentar que redes mais abertas, menos coesas, permitem a introdução de novas ideias ou oportunidades aos seus membros, fazendo com que laços mais fracos (nodos) sejam também vantajosos para a expansão futura e força da rede, pois se torna permeável à inovação e a ideias disruptivas, capazes de gerar quebras de paradigmas e romper o consenso formado por autores estabelecidos (Vanz, 2013).

\section{QUADRO 1 CARACTERÍSTICAS DAS REDES PAB E PASB, 2015}

\begin{tabular}{|c|c|c|}
\hline Característica da Rede & PAB & Pasb \\
\hline CONECTIVIDADE & $\begin{array}{l}\text { Rede conectada (todos os pares de } \\
\text { nodos são alcançáveis) }\end{array}$ & $\begin{array}{l}\text { Rede conectada (todos os pares de } \\
\text { nodos são alcançáveis) }\end{array}$ \\
\hline \multirow{2}{*}{$\begin{array}{l}\text { (Cut point - único responsável pela } \\
\text { comunicação de determinados nodos) }\end{array}$} & — 29 nós e 380 laços & — 46 nós e 292 laços \\
\hline & Presença de cut point (Hunter 2007) & Ausência de cut point \\
\hline K CORE — no de ligações mínimas que & Subgrupo formado por 17 nós com & k core com variação pequena (2 a 5) \\
\hline "seguram" o nodo na rede $\quad{ }^{\cdot \cdots-\cdots}$ & k core mínimo 12 & e mais equilibrada \\
\hline $\begin{array}{l}\text { DENSIDADE - proporção de linhas } \\
\text { presentes em relação ao total de linhas } \\
\text { possíveis, considerando-se o número } \\
\text { total de nodos }\end{array}$ & $\begin{array}{l}82,7 \% \text { dos nós têm densidade igual } \\
\text { ou maior que } 0,70\end{array}$ & $\begin{array}{l}28,2 \% \text { dos nós têm densidade igual } \\
\text { ou maior que } 0,70\end{array}$ \\
\hline $\begin{array}{l}\text { CENTRALIDADE DE PROXIMIDADE - } \\
\text { posição mais "visível" medida a partir } \\
\text { do ator (autor) mais central; será zero } \\
\text { quando todos os nodos tiverem a mesma } \\
\text { centralidade }\end{array}$ & Variação de 35 a 77 & Variação de 95 a 122 \\
\hline $\begin{array}{l}\text { GRAU DE VIZINHANÇA - no de ligações } \\
\text { que partem do nodo }\end{array}$ & $\begin{array}{l}\text { Variação de } 1 \text { a } 22 \\
\text { Grau médio - 13,1 }\end{array}$ & $\begin{array}{l}\text { Variação de } 2 \text { a } 12 \\
\text { Grau médio - 6,3 }\end{array}$ \\
\hline
\end{tabular}

Fonte: Dados da pesquisa (2015).

Após a clusterização das redes utilizando o programa Ucinet, com dois agrupamentos, foram observados na rede $\mathrm{PAB}$ dois subgrupos com temáticas diferentes (conteúdo das obras publicadas) - conforme figura 4.

O cluster 1, com 23 nós, revela publicações majoritariamente relacionadas com estudos sociopolíticos de um programa de orçamento participativo (OP), implantado em Porto Alegre em 1989, que 
reaparece em outros artigos e livros do mesmo cluster, trazendo exemplos de democracia participativa, democracia deliberativa e governança, sempre dentro da perspectiva brasileira e latino-americana; além disso, há outros trabalhos que incluem temáticas como capital social, o Partido dos Trabalhadores e as eleições presidenciais de 2006.

O cluster 2, com apenas 6 nós, apresenta temas relacionados com o desmatamento da Amazônia, além de duas obras com ideias divergentes: a conhecida teoria de "Hardin" ("A tragédia dos comuns"), que trata do livre acesso a recursos comuns, gerando inevitavelmente exploração excessiva de tais recursos, e o livro de "Ostrom" ("Governing the commons"), que se opõe a essa teoria, propondo que na maioria das vezes as pessoas fazem uso dos recursos comuns com equilíbrio.

Para ilustrar os conteúdos dominantes nos clusters na rede PAB, os títulos das respectivas publicações foram inseridos em um aplicativo de livre acesso, criador de "nuvem de palavras" (www. tagxedo.com) - figura 5.

\section{FIGURA 4 REPRESENTAÇÃO GRÁFICA DA REDE PAB, 2015}

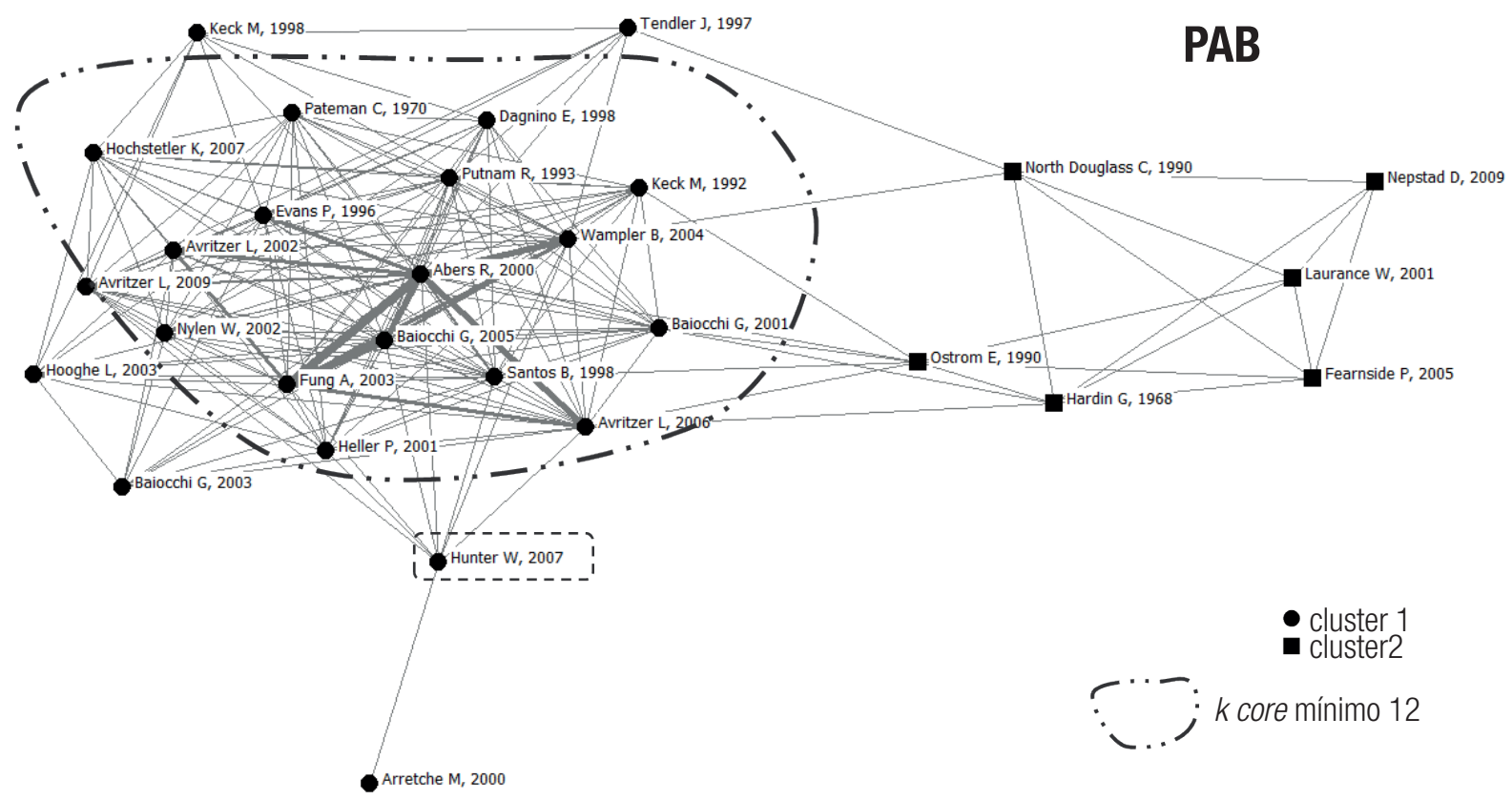

Fonte: Dados da pesquisa (2015).

Os dois clusters formados na rede Pasb estão representados na figura 6, denominados 3 e 4 . O cluster 3, com 21 nós, contém textos importantes a respeito de Modelos de Atenção em Saúde, publicações a respeito do SUS (contextualização histórica, avanços, financiamento e práticas de gestão descentralizada); dois documentos relacionados com métodos: "Triola" - Estatística, e "Yin" - Estudo de Caso; além da clássica abordagem do Planejamento Estratégico Situacional de "Carlos Matus", de 1993. Os autores relacionados com os modelos de atenção são: "Hartz" (integralidade da atenção), "Mendes” (redes de atenção), "Starfield” (atenção primária), "Campos” (Paidea), 
"Schimidt" (contexto doenças crônicas não transmissíveis) e "Fonseca" (modelo de prestação de serviços públicos de saúde da época Vargas). O cluster 4 contém a Constituição Federal de 1988, juntamente com diversas publicações mais relacionadas com modelos de gestão: implantação das reformas sanitárias, impactos da descentralização na administração pública, práticas de gestão e questões de financiamento do SUS (mecanismos de regulação e relação com o setor privado). Permanece a experiência do orçamento participativo de Porto Alegre e os artigos a respeito de democracia participativa. Este cluster revela ainda dois artigos correlatos a modelos de atenção, com o tema de vigilância em saúde.

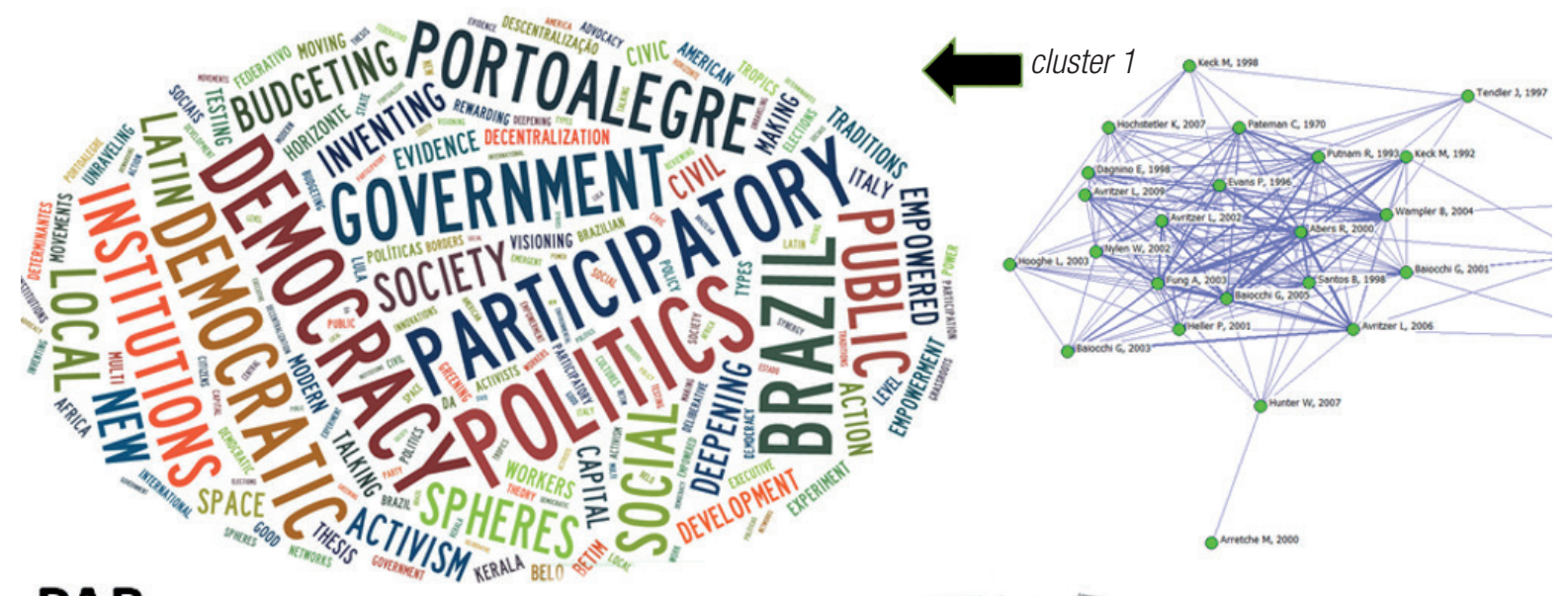

PAB
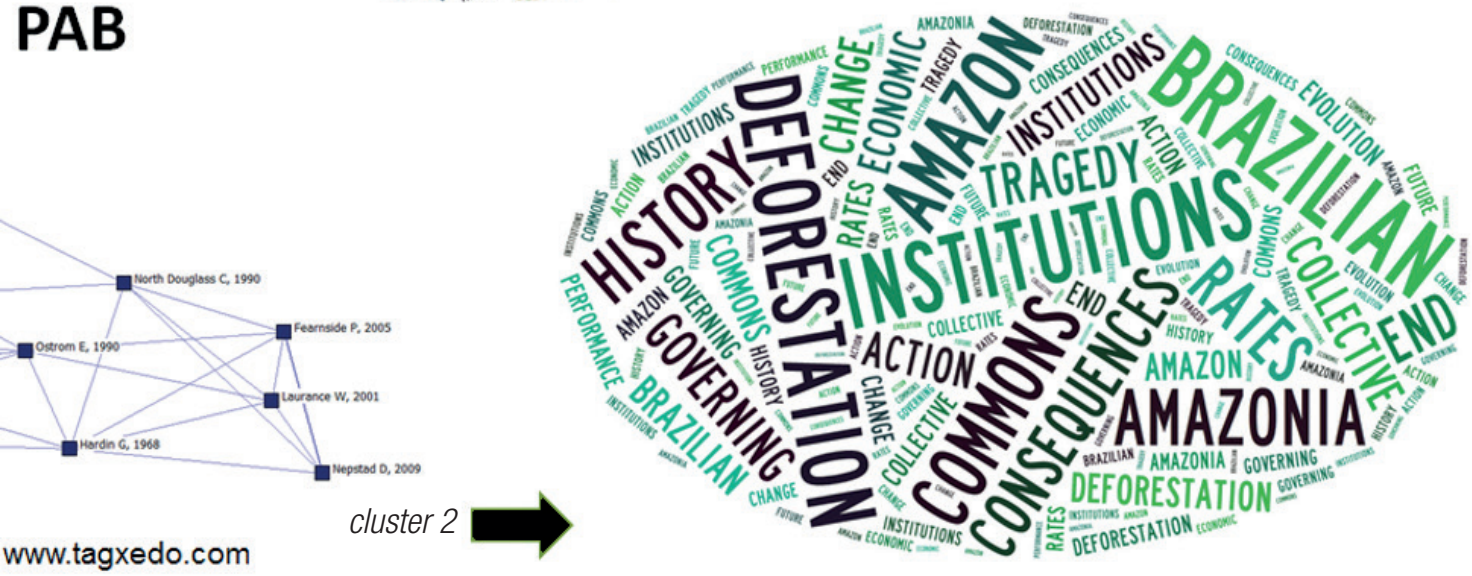

Fonte: Dados da pesquisa (2015).

Os títulos destas publicações (rede Pasb) também foram inseridos em um site de livre acesso, criador de "nuvem de palavras" (www.tagxedo.com), porém, nesse caso, as palavras em inglês foram traduzidas para o português, para que não houvesse perda de força da palavra pelo fato de estarem em idiomas diferentes (figura 7). 
FIGURA 6 REPRESENTAÇÃO GRÁFICA DA REDE PASB, 2015

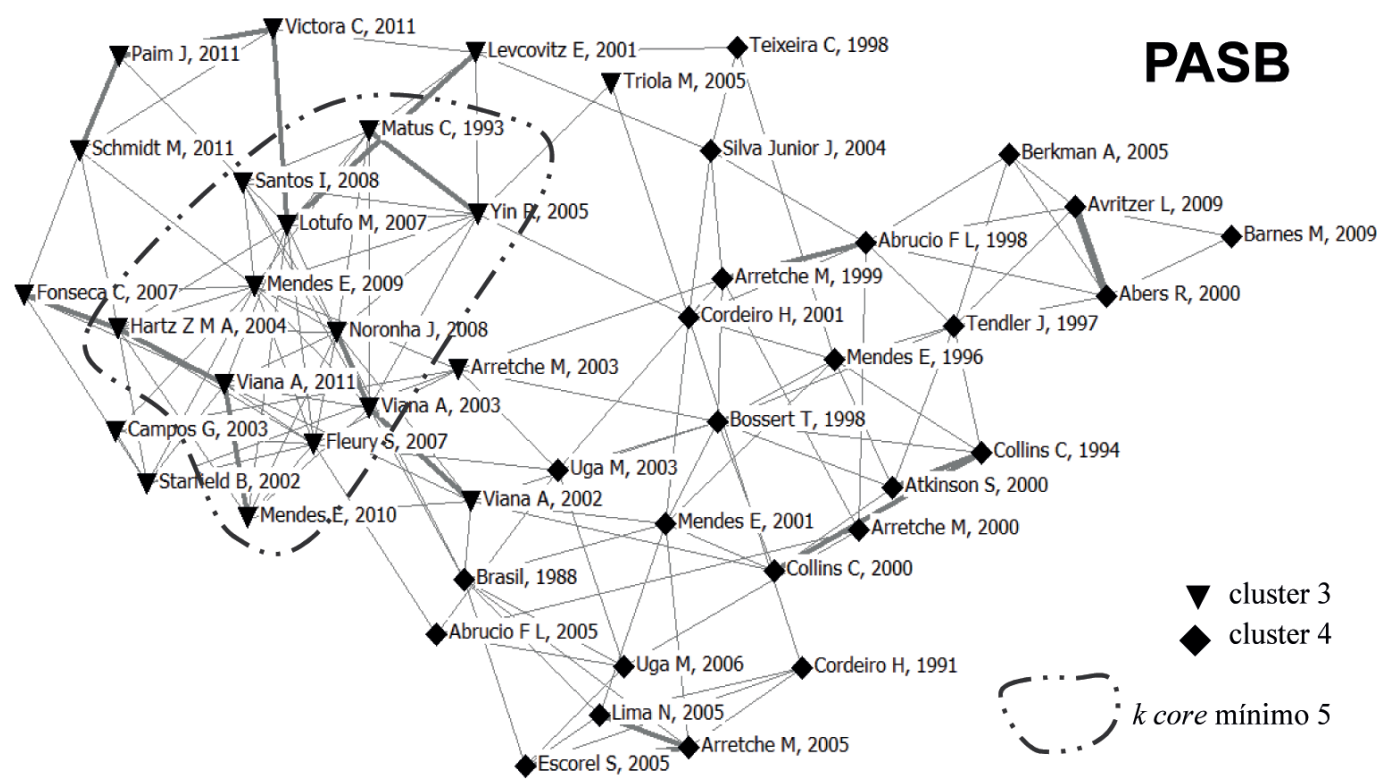

Fonte: Dados da pesquisa (2015).

FIGURA 7 NUVEM DE PALAVRAS FORMADA COM OS TíTULOS DAS PUBLICAÇÕES DOS CLUSTERS 3 E 4 DA REDE PASB, 2015
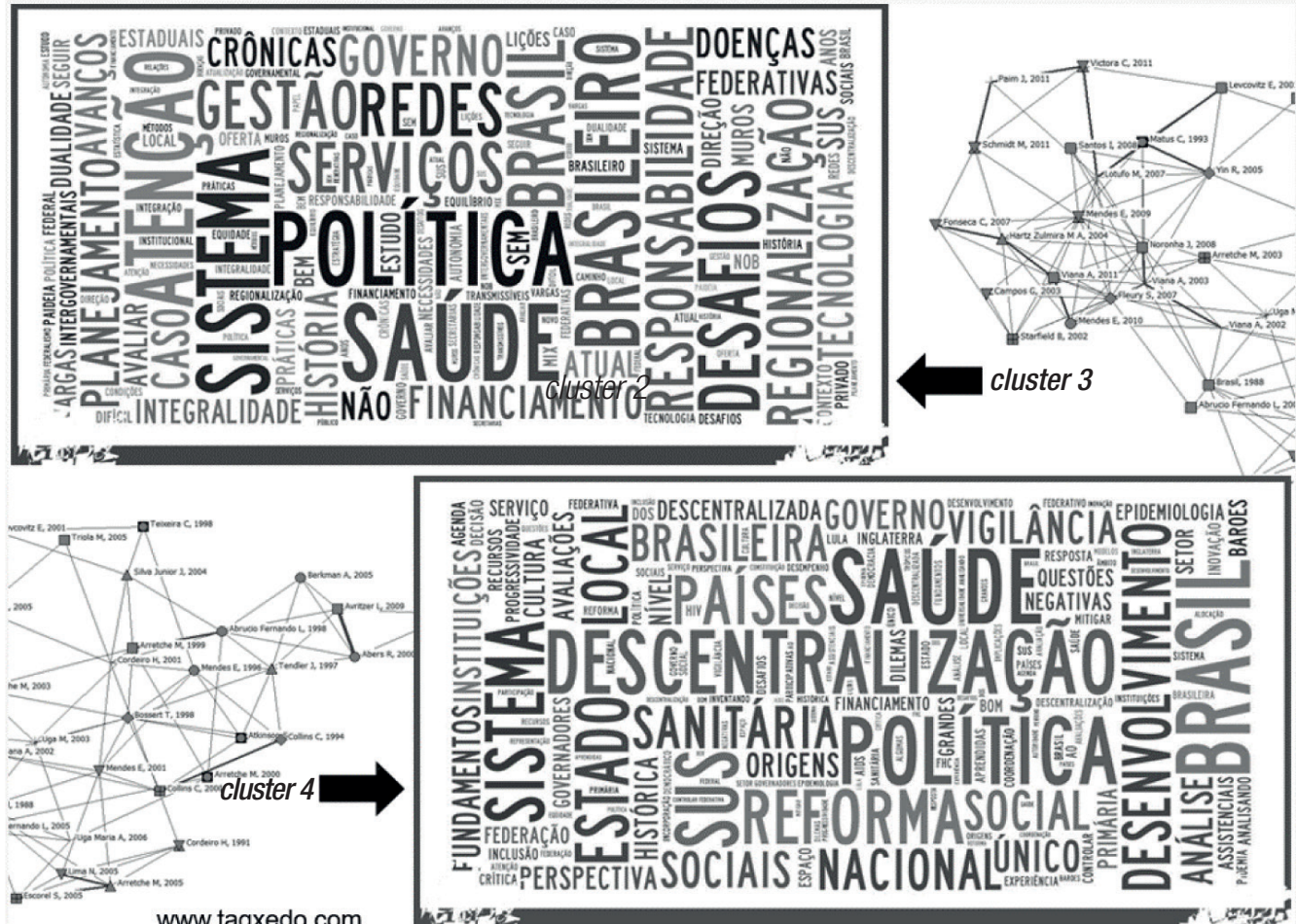

Fonte: Dados da pesquisa (2015). 
A partir dos atributos "centralidade de proximidade" e "grau de vizinhança", foi possível identificar, nas redes PAB e Pasb, as publicações (e autores) de maior influência para cada rede, representados nas figuras 8 e 9 e nos quadros 2 e 3 .

A rede $\mathrm{PAB}$ reconfigurada (figura 8 e quadro 2) conta com 10 autores e 13 publicações, sendo seis em formato de livro e sete em formato de artigo, no período de 1993 a 2009.

\section{FIGURA 8 REDE PAB COM IDENTIFICAÇÃO DOS ATRIBUTOS “CENTRALIDADE" E "GRAU DE} VIZINHANÇA” (CINCO PRIMEIROS NÍVEIS) — REDE PAB RECONFIGURADA, 2015

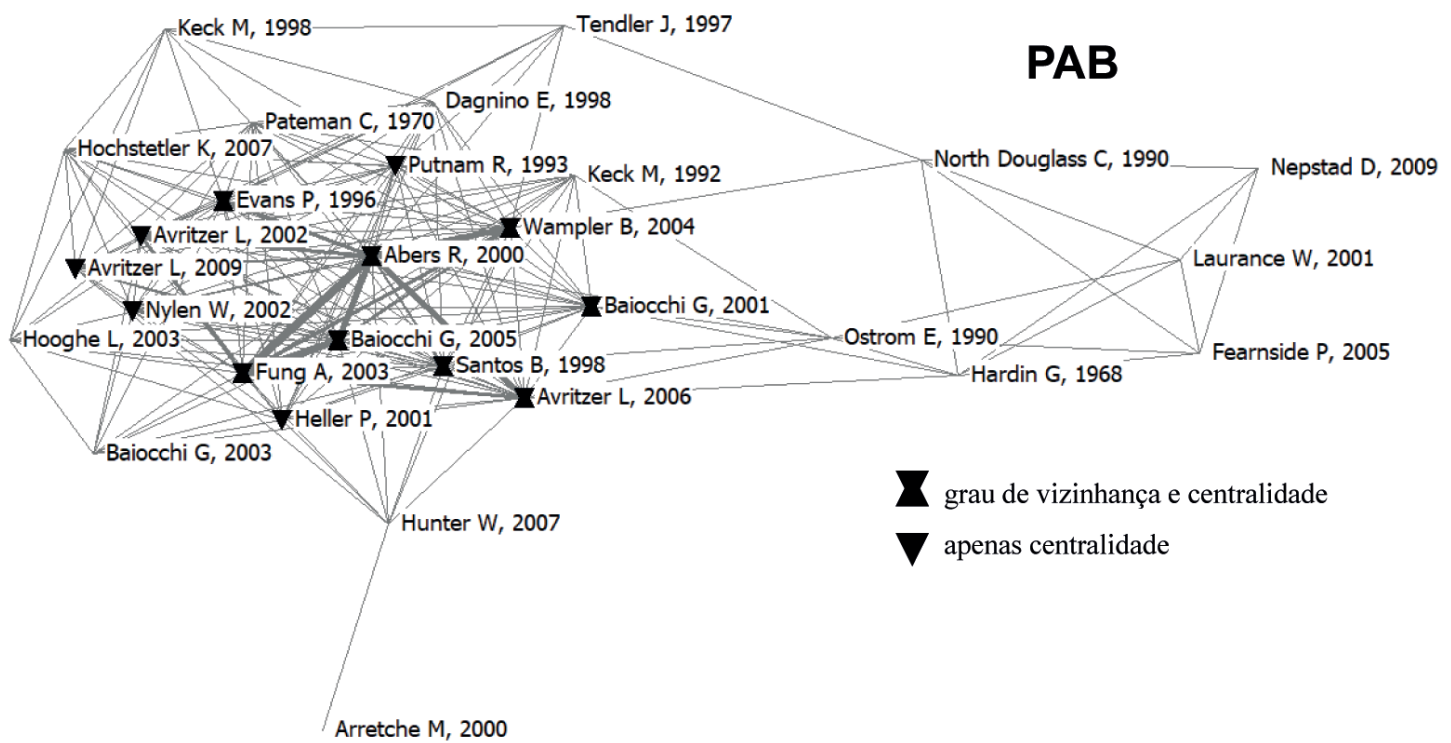

Fonte: Dados da pesquisa (2015).

Como os nós identificados faziam parte do cluster 1, o conteúdo temático recorrente é o já mencionado: experiência de orçamento participativo em Porto Alegre (e outros locais), democracia deliberativa, democracia da América Latina e capital social.

\section{QUADRO 2 RELAÇÃO (EM ORDEM ALFABÉTICA) DOS AUTORES E PUBLICAÇÕES, REFERENTES À REDE PAB RECONFIGURADA, 2015}

\begin{tabular}{l|lll} 
Autor, ano & $\begin{array}{c}\text { Tipo de } \\
\text { publicação }\end{array}$ & \multicolumn{1}{c}{ Título } & \multicolumn{1}{c}{ Foco principal } \\
\hline Abers R, $\mathbf{2 0 0 0}$ & Livro & $\begin{array}{l}\text { Inventing local democracy: } \\
\text { grassroots politics in Brazil }\end{array}$ & $\begin{array}{l}\text { Trajetória sociopolítica e impacto do programa de OP } \\
\text { (1989), Porto Alegre }\end{array}$ \\
\hline Avritzer L, 2002 & Livro & $\begin{array}{l}\text { Democracy and the public space in } \\
\text { Latin America }\end{array}$ & $\begin{array}{l}\text { Estudo da democracia na América Latina, fazendo } \\
\text { distinção à democracia restrita, elitista, europeia. }\end{array}$ \\
\hline Avritzer L, 2006 & Artigo & $\begin{array}{l}\text { New public spheres in Brazil: local } \\
\text { democracy and deliberative politics }\end{array}$ & $\begin{array}{l}\text { Expansão do OP e reflexo nas características } \\
\text { deliberativas e distributivas }\end{array}$ \\
\hline
\end{tabular}




\begin{tabular}{|c|c|c|c|}
\hline Autor, ano & $\begin{array}{c}\text { Tipo de } \\
\text { publicação }\end{array}$ & Título & Foco principal \\
\hline Avritzer L, 2009 & Livro & $\begin{array}{l}\text { Participatory institutions in } \\
\text { democratic Brazil }\end{array}$ & $\begin{array}{l}\text { Democracia participativa — caso Porto Alegre, São } \\
\text { Paulo, Salvador. Análise do OP, conselhos de saúde e } \\
\text { planos pilotos }\end{array}$ \\
\hline $\begin{array}{l}\text { Baiocchi G, } \\
2001\end{array}$ & Artigo & $\begin{array}{l}\text { Participation, activism, and politics: } \\
\text { the Porto Alegre experiment and } \\
\text { deliberative democratic theory }\end{array}$ & $\begin{array}{l}\text { Experiência de Porto Alegre — análise da } \\
\text { participação populacional segundo renda, gênero e } \\
\text { educação, e relação com a democracia deliberativa }\end{array}$ \\
\hline $\begin{array}{l}\text { Baiocchi G, } \\
2005\end{array}$ & Livro & $\begin{array}{l}\text { Militants and citizens: the politics } \\
\text { of participatory democracy in Porto } \\
\text { Alegre }\end{array}$ & $\begin{array}{l}\text { Experiência de Porto Alegre - estudo político- } \\
\text { cultural da governança e democracia participativa }\end{array}$ \\
\hline Evans P, 1996 & Artigo & $\begin{array}{l}\text { Government action, social capital } \\
\text { and development: reviewing the } \\
\text { evidence on synergy }\end{array}$ & $\begin{array}{l}\text { Explora formas e recursos de sinergia Estado- } \\
\text { sociedade }\end{array}$ \\
\hline Fung A, 2003 & Livro & $\begin{array}{l}\text { Deepening democracy: institutional } \\
\text { Innovations in empowered } \\
\text { participatory Governance }\end{array}$ & $\begin{array}{l}\text { Estudo sobre democracia deliberativa, mostrando } \\
\text { casos de Porto Alegre, Chicago, gestão ambiental e } \\
\text { Kerala }\end{array}$ \\
\hline Heler P, 2001 & Artigo & $\begin{array}{l}\text { Moving the State: the politics of } \\
\text { democratic decentralization in } \\
\text { Kerala, South Africa, and Porto } \\
\text { Alegre }\end{array}$ & $\begin{array}{l}\text { Estudo da democracia a partir das experiências de } \\
\text { Porto Alegre e Kerala }\end{array}$ \\
\hline Nylen W, 2002 & Artigo & $\begin{array}{l}\text { Testing the empowerment thesis: } \\
\text { the participatory budget in Belo } \\
\text { Horizonte and Betim, Brazil }\end{array}$ & $\begin{array}{l}\text { OP em Belo Horizonte e Betim como exemplo de } \\
\text { empoderamento de cidadãos }\end{array}$ \\
\hline $\begin{array}{l}\text { Putnam R, } \\
1993\end{array}$ & Livro & $\begin{array}{l}\text { Making democracy work: civic } \\
\text { traditions in modern Italy }\end{array}$ & $\begin{array}{l}\text { Relação do capital social na comunidade cívica e } \\
\text { instituições de sucesso }\end{array}$ \\
\hline Santos B, 1998 & Artigo & $\begin{array}{l}\text { Participatory budgeting in Porto } \\
\text { Alegre: toward a redistributive } \\
\text { democracy }\end{array}$ & $\begin{array}{l}\text { Análise do caso Porto Alegre na perspectiva das } \\
\text { instituições, processos e critérios da distribuição dos } \\
\text { recursos }\end{array}$ \\
\hline $\begin{array}{l}\text { Wampler B, } \\
2004\end{array}$ & Artigo & $\begin{array}{l}\text { Participatory publics: civil society } \\
\text { and new institutions in democratic } \\
\text { Brazil }\end{array}$ & $\begin{array}{l}\text { OP em Porto Alegre, Belo Horizonte, Recife } \\
\text { evidenciando as organizações da sociedade civil } \\
\text { e reformadores políticos para implementar novos } \\
\text { sistemas de formulação de políticas }\end{array}$ \\
\hline
\end{tabular}

Fonte: Dados da pesquisa (2015).

A experiência de Porto Alegre em OP foi considerada importante anos atrás, e utilizada para exemplificar a possibilidade de políticas ativas de reforma democrática, por meio de ambiente interativo favorável a fim de fortalecer grupos locais da sociedade civil (Frey, 2007). O OP e os conselhos 
comunitários foram exemplos do esforço de implementação de políticas públicas participativas, impulsionadas por organismos multilaterais, mandamentos constitucionais e compromissos assumidos por alguns partidos políticos, e essas práticas divergem do modelo do "novo gerencialismo público" (Souza, 2006). Ainda assim, há menção ao OP como uma criação interessante, relacionando-a com um espaço público não estatal, dentro da perspectiva de delimitação da área de atuação do Estado (Bresser-Pereira, 1997). Em outra revisão, o OP é citado como exemplo de mecanismo da democracia deliberativa, assim como o fortalecimento da comunidade na gestão e planejamento participativo, sob a ótica do modelo de governança participativa (Secchi, 2009).

Em um estudo a respeito dos aspectos culturais e sociais do orçamento participativo em Porto Alegre e Belo Horizonte e sua expansão no Brasil, o autor considera fatores específicos de algumas cidades como a tradição em se organizar por associações e a participação comunitária, que favorece a negociação entre associações comunitárias e a administração pública. Refere-se também a cidades que não têm uma sociedade participante e nesses casos a prática de OP é realizada de forma mais simplificada. Além disso, faz referência dessa política ao Partido dos Trabalhadores (ou a partidos populares de esquerda) (Avritzer, 2005).

De acordo com outro autor (Abrúcio, 2011), a escolha pela ampliação dos mecanismos participativos é, evidentemente, mérito da gestão Lula; porém, houve dificuldades em se lidar com a ampliação da democracia deliberativa ao invés do jogo tradicional de coalizão para governabilidade, sob o presidencialismo da democracia representativa brasileira, percebida nos modelos de relacionamento com o Congresso Nacional, baseados principalmente na troca de cargos e verbas por apoio.

A administração deliberativa participativa pretende incorporar ao funcionamento da administração pública elementos de natureza política como o diálogo e a negociação. Modernizá-la deve ter como objetivo, não a eficiência instrumental, como é o caso da nova gestão pública, mas responder às exigências e às demandas de uma nova ordem social; ou seja, as respostas não precisam ser tecnicamente melhores nem mais rápidas, mas devem representar um ponto de equilíbrio, um compromisso entre as diversas visões de um mesmo problema (Brugué, 2004).

Dois autores, "Putnam" e "Evans", remetem ao conceito de capital social, conjunto de normas de reciprocidade, confiança e sentimento de pertencimento, possibilitando maior engajamento cívico e participação comunitária. A geração de capital social, assim como a criação de valores públicos, a coordenação de atores públicos e privados, inclusão social e compartilhamento de responsabilidades devem fazer parte de um rol de ações inovadoras essenciais para o Estado enfrentar as grandes mudanças das últimas décadas (Matias Pereira, 2010).

A partir da racionalidade deliberativa é possível olhar para as questões públicas sob diferentes pontos de vista, para lidar com problemas complexos, por meio do diálogo e de forma democrática. Assim, para que uma política pública tenha sucesso, é necessário incluir as opiniões de todas as partes pela política do diálogo, gerando inteligência em seu conteúdo, sem dissociar da forma. Por meio de processos participativos, geram-se sinergia e capital social suficientes para se concretizar políticas, superando os problemas de não concordância de alguns e interesses particulares (Tarragó, Brugué e Cardoso Júnior, 2015).

Agora, a rede Pasb reconfigurada (figura 9 e quadro 3) conta com 12 autores e 16 publicações, sendo oito em formato de livro, sete em formato de artigo e uma em formato de lei, compreendendo o período de 1988 a 2011. 


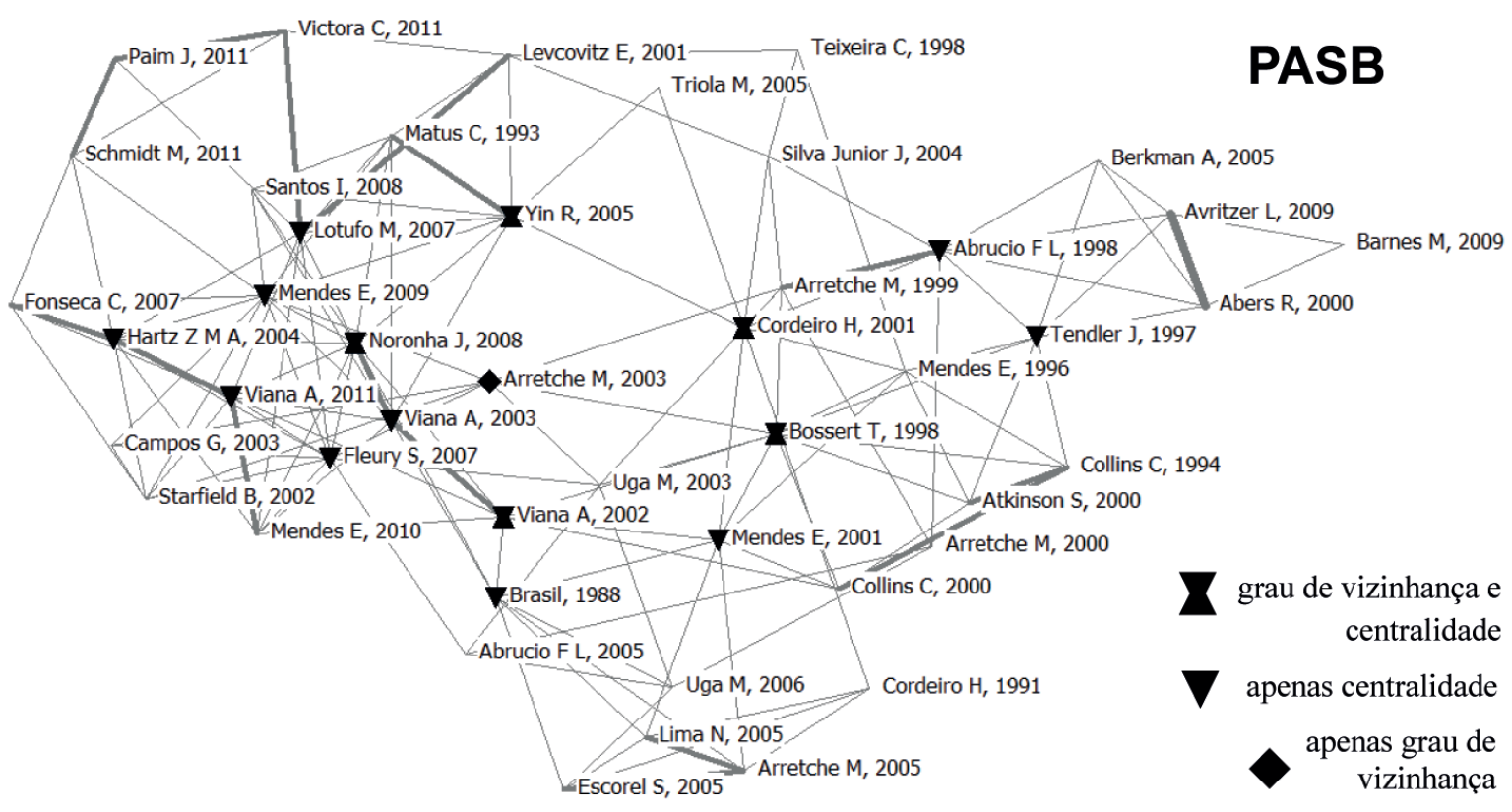

Fonte: Dados da pesquisa (2015).

Os nós identificados têm origem nos dois clusters e o conteúdo das publicações inclui, principalmente, textos relacionados com descentralização do sistema de saúde e também com verificação de práticas de gestão local ou regional, formulação ou avaliação de modelos de atenção, a Constituição Federal, e método de pesquisa de Yin.

Além de ser uma diretriz do SUS, a lógica da descentralização remete, em parte, ao intuito de melhorar a efetividade, considerando-se que em unidades mais próximas da realidade os usuários prestarão melhores serviços. Também encontra justificativa nas bases democráticas, com maiores oportunidades às pessoas de se envolverem nos níveis locais da administração (Peters, 2008).

Antes mesmo da criação do SUS, alguns municípios já tinham papel decisivo em vários estados, como nas políticas de erradicação da poliomielite (paralisia infantil) e sarampo (Santos, 2013b). Apesar disso, pode não haver garantia intrínseca na relação entre a autonomia dos governos locais e o compromisso com as necessidades dos cidadãos e nem com a eficiência da administração (Arretche, 2003). Da mesma forma, processos de descentralização podem gerar problemas de coordenação e a necessidade de se centrar nas interações que ocorrem na prestação de serviços (Carneiro e Menicucci, 2011). Argumenta-se que seus mecanismos de operação estão institucionalizados, porém a diretriz não deve ser um fim em si mesma (Viana, Lima e Oliveira, 2002). Por um lado, a gestão local é limitada pelo expressivo poder de indução do governo central; por outro, os cidadãos dispõem de instrumentos para controlar e fiscalizar a ação dos governos locais, mas não os exploram totalmente (Arretche, 2003).

As publicações na rede Pasb reconfigurada, no quadro 3, levantam algumas questões a respeito da descentralização, vinculadas ao financiamento, complexidade do sistema e desigualdades regionais. 


\section{QUADRO 3 RELAÇÃO (EM ORDEM ALFABÉTICA) DOS AUTORES E PUBLICAÇÕES, REFERENTES À REDE PASB RECONFIGURADA, 2015}

\begin{tabular}{|c|c|c|c|}
\hline Autor, ano & $\begin{array}{l}\text { Tipo de } \\
\text { publicação }\end{array}$ & Título & Foco principal \\
\hline Abrucio F, 1998 & Livro & $\begin{array}{l}\text { Os Barões da federação: os } \\
\text { governadores e a redemocratização } \\
\text { brasileira }\end{array}$ & $\begin{array}{l}\text { Compreensão das relações entre União, estados } \\
\text { e municípios no sistema político brasileiro e } \\
\text { repercussões }\end{array}$ \\
\hline $\begin{array}{l}\text { Arretche M, } \\
2003\end{array}$ & Artigo & $\begin{array}{l}\text { Financiamento federal e gestão } \\
\text { local de políticas sociais: o } \\
\text { dificil equilibrio entre regulação, } \\
\text { responsabilidade e autonomia }\end{array}$ & $\begin{array}{l}\text { Análise dos mecanismos institucionais e sua } \\
\text { relação com a qualidade da atenção à saúde }\end{array}$ \\
\hline Bossert T, 1998 & Artigo & $\begin{array}{l}\text { Analyzing the decentralization } \\
\text { of health systems in developing } \\
\text { countries: decision space, } \\
\text { innovation and performance }\end{array}$ & $\begin{array}{l}\text { Avaliação crítica da descentralização dos } \\
\text { sistemas de saúde na América Latina, quanto } \\
\text { a equidade, eficiência, qualidade, desempenho, } \\
\text { além de explorar o espaço de decisão local }\end{array}$ \\
\hline Brasil, 1988 & Conjunto de leis & Constituição Federal do Brasil & $\begin{array}{l}\text { Documento oficial e vigente, elaborado por } \\
\text { deputados e senadores, contendo normas, } \\
\text { direitos e deveres dos cidadãos e Estado }\end{array}$ \\
\hline Cordeiro H, 2001 & Artigo & $\begin{array}{l}\text { Descentralização, universalidade e } \\
\text { equidade nas reformas da saúde }\end{array}$ & $\begin{array}{l}\text { Contextualização da saúde pública na década de } \\
\text { 1990, a partir dos princípios constitucionais e } \\
\text { da onda neoliberal que influenciou reformas na } \\
\text { América Latina }\end{array}$ \\
\hline Fleury S, 2007 & Livro & $\begin{array}{l}\text { Gestão de redes: a estratégia de } \\
\text { regionalização da política de saúde }\end{array}$ & $\begin{array}{l}\text { Discussão do tema redes na perspectiva da } \\
\text { gestão e das políticas públicas, regionalização } \\
\text { do SUS e norma de operacionalização de } \\
\text { assistência à saúde (Noas) }\end{array}$ \\
\hline Hartz Z, 2004 & Artigo & $\begin{array}{l}\text { Integralidade da atenção e } \\
\text { integração de serviços de saúde: } \\
\text { desafios para avaliar a implantação } \\
\text { de um "sistema sem muros" }\end{array}$ & $\begin{array}{l}\text { Compartilhamento de experiências, "lições } \\
\text { aprendidas" sobre a integração de serviços, } \\
\text { interesse comum a pesquisadores e gestores }\end{array}$ \\
\hline Lotufo M, 2007 & Artigo & $\begin{array}{l}\text { Sistemas de direção e práticas } \\
\text { de gestão governamental em } \\
\text { secretarias estaduais de Saúde }\end{array}$ & $\begin{array}{l}\text { Estudo de caso de } 12 \text { secretarias estaduais de } \\
\text { saúde, apresentando processos de formulação } \\
\text { de políticas, tomada de decisões, implementação } \\
\text { de programas }\end{array}$ \\
\hline Mendes E, 2001 & Livro & Os grandes dilemas do SUS & $\begin{array}{l}\text { Trata da reforma sanitária no Brasil, os objetivos e a } \\
\text { complexidade dos sistemas de serviços de saúde }\end{array}$ \\
\hline Mendes E, 2009 & Livro & As redes de atenção à saúde & $\begin{array}{l}\text { Proposta de implantação de redes de atenção à } \\
\text { saúde, condições agudas e crônicas, gestão da } \\
\text { clínica, integralidade, atuação nos determinantes } \\
\text { sociais e formas alternativas de financiamento }\end{array}$ \\
\hline
\end{tabular}




\begin{tabular}{|c|c|c|c|}
\hline Autor, ano & $\begin{array}{c}\text { Tipo de } \\
\text { publicação }\end{array}$ & Título & Foco principal \\
\hline Noronha J, 2008 & Livro (capítulo) & O Sistema Único de Saúde (SUS) & $\begin{array}{l}\text { Análise dos principais aspectos que orientaram a } \\
\text { implantação SUS até o final da década de } 2000 \text {, } \\
\text { apresentando avanços e desafios }\end{array}$ \\
\hline Tendler J, 1997 & Livro & Good government in the tropics & $\begin{array}{l}\text { Aborda quatro projetos do governo cearense, } \\
\text { levantando questões sobre a organização } \\
\text { do setor e prestação de serviços públicos, } \\
\text { descentralização e interação entre governo e } \\
\text { sociedade civil }\end{array}$ \\
\hline Viana A, 2002 & Artigo & $\begin{array}{l}\text { Descentralização e federalismo: a } \\
\text { política de saúde em novo contexto } \\
\text { — lições do caso brasileiro }\end{array}$ & $\begin{array}{l}\text { Análise dos processos de descentralização e } \\
\text { implicações nas reformas recentes da política } \\
\text { de saúde: limites e riscos, no contexto das } \\
\text { desigualdades }\end{array}$ \\
\hline Viana A, 2003 & Artigo & Política de saúde e equidade & $\begin{array}{l}\text { Análise da oferta e utilização de serviços em } \\
\text { saúde, alocação de recursos municipais, na } \\
\text { perspectiva da equidade }\end{array}$ \\
\hline Viana A, 2011 & Livro & $\begin{array}{l}\text { Regionalização e relações } \\
\text { federativas na política de saúde no } \\
\text { Brasil }\end{array}$ & $\begin{array}{l}\text { Análise da regionalização em saúde nos estados, } \\
\text { verificando os condicionantes do processo e } \\
\text { as dinâmicas de funcionamento das instâncias } \\
\text { colegiadas }\end{array}$ \\
\hline Yin R, 2005 & Livro & $\begin{array}{l}\text { Estudo de caso, planejamento e } \\
\text { métodos }\end{array}$ & Clássico método de pesquisa \\
\hline
\end{tabular}

Fonte: Dados da Pesquisa (2015).

Outra publicação que se destaca na rede Pasb reconfigurada é a Constituição de 1988. Esta definiu uma concepção de democracia e seguridade social como expressão dos direitos sociais inerentes à cidadania, integrando saúde, previdência e assistência. Reconheceu o direito à saúde e o dever do Estado, mediante a garantia de um conjunto de políticas econômicas e sociais, com a criação do Sistema Único de Saúde, universal, público, participativo, descentralizado e integral (Paim, 2013).

O tema SUS é encontrado em outras publicações da rede, tendo em vista que talvez seja o resultado mais concreto relacionado com a saúde na Constituição. Os argumentos variam, desde uma perspectiva mais ampla, apresentando objetivos do sistema e complexidade como em "Mendes, 2001", mecanismos de implementação, em "Arretche", e análises dos processos de formulação e implementação de programas, em "Lotufo" e "Noronha". Entre os modelos de atenção presentes na rede Pasb, permanecem na rede reconfigurada aqueles relacionados com o princípio da integralidade: integração dos serviços e redes de atenção - "Hartz", "Fleury" e "Mendes, 2009".

Em 2010, 85\% dos municípios brasileiros já dispunham de programas apoiadores da Atenção Primária, como o Programa de Agentes Comunitários de Saúde e a Estratégia de Saúde da Família (ESF). Essa grande expansão, impulsionada pela descentralização da gestão e estratégias de repasse de recursos do governo federal, tem estimulado os municípios a investirem em sistemas regulatórios e criarem estratégias para a integração do cuidado primário com a rede de serviços especializados (Paim et al., 2011). 


\section{CONSIDERAÇÕES FINAIS}

Este trabalho teve como objetivo identificar a publicação internacional indexada na WoS, a respeito da administração pública no Brasil, sob a vertente da saúde. Na análise não se observou um autor ou publicação que tenha se destacado de forma isolada; desse modo, a interpretação foi realizada a partir das relações dos nós (publicações) nas redes.

A partir da análise das redes sociais da administração pública, foi possível identificar uma rede bastante coesa associada a práticas de sucesso de orçamentos participativos, relacionados com democracia deliberativa e participação social. Por um lado, a força dessas publicações valoriza as conquistas constitucionais e registra modelos inovadores de gestão; por outro, pode-se argumentar que a grande coesão entre essas publicações poderia restringir a inserção de novas ideias ou novas práticas nas redes constituídas.

Não se verificam, nas redes, documentos a respeito da "nova gestão pública". Considerando que esse modelo faz parte da história brasileira, é preciso interrogar se não existem estudos a respeito (algo bastante improvável), ou se apenas não foram publicados internacionalmente e indexados na WoS, e, portanto, não aparecem nas redes analisadas.

De acordo com um trabalho realizado com editores de periódicos científicos, há relação entre produção e publicação científica. As revistas são responsáveis pela circulação do debate acadêmico e científico; também são, de certo modo, indutoras da definição editorial de temas, teoria e métodos relevantes para determinada época e público, que podem se tornar hegemônicos para determinar o "espírito de uma época" (Valmore, 2015).

$\mathrm{Na}$ análise da rede da administração pública da saúde, em que as conexões foram menos densas, percebeu-se uma variação maior de temas, com destaque para a Reforma Sanitária Brasileira e a descentralização do SUS. Além disso, há diversos trabalhos com enfoque mais reflexivo, questionando a eficiência nos serviços de saúde e mecanismos de controle do SUS, bem como a equidade na desconcentração dos serviços. Há publicações a partir de práticas locais, como também produções contextualizando a situação do país, modelos teóricos e relação entre os níveis da gestão. O tema da participação comunitária, tão presente na rede $\mathrm{PAB}$, não apareceu na rede Pasb. O fato é intrigante ao se pensar que o SUS possui uma lei própria para o controle social, para ajudar a tomar decisões na saúde. Nesse caso, também se faz necessário investigar qual o significado da ausência de publicações desse tema. Provavelmente, isso se deve à principal limitação do estudo que é se ater somente à exploração da base bibliográfica WoS e utilizar algoritmos para a obtenção dos metadados analisados. Por outro lado, o que parece ser uma limitação também pode ser visto por outra perspectiva, como uma possibilidade de inovação metodológica e de exploração do quanto essa temática consegue inserção internacional.

Considerando que as grandes reformas, tanto na administração como na saúde pública brasileira, têm origem na Constituição e, portanto, são relativamente recentes, verifica-se que sua compreensão tem evoluído de forma técnica e política, com presença de criticidade, mas que ainda abre lacunas e permite a exploração de novos caminhos. 


\section{REFERÊNCIAS}

ABRÚCIO, Fernando L. Trajetória recente da gestão pública brasileira: um balanço crítico e a renovação da agenda de reformas. Rev. Adm. Pública, Rio de Janeiro, edição especial comemorativa, p. 67-86, 2007.

ABRÚCIO, Fernando L. Três agendas, seus resultados e um desafio: balanço recente da administração pública federal brasileira. Desigualdade \& Diversidade, dossiê especial, p. 119-142, 2011.

ALONSO, Luiza B. N.; HEDlER, Helga C.; CASTILHO, Suely B. Sistema Único de Saúde: a busca do entendimento de seus princípios e sistemas de valores para profissionais do serviço público. Revista do Serviço Público, v. 61, n. 4, p. 371-386, 2010.

ARRETCHE, Marta. Financiamento federal e gestão local de políticas sociais: o difícil equilíbrio entre regulação, responsabilidade e autonomia. Ciência \& Saúde Coletiva, v. 8, n. 2, p. 331-345, 2003.

AVRITZER, Leonardo. New public spheres in Brazil: local democracy and deliberative politics. Revista Direito GV, n. esp., n. 1, p. 55-74, 2005.

BARROS, Maria E.; PIOLA, Sérgio F.; VIANNA, Solon M. Política de saúde no Brasil: diagnóstico e perspectivas. Brasília: Ipea, 1996.

BORGATTI, Steve P.; EVERETT, Martin G.; FREEMAN, Lin C. Ucinet 6 for Windows: software for social network analysis. Harvard, MA: Analytic Thecnologies, 2002.

BRASIL. Lei $n^{\circ}$ 8.080. Dispõe sobre as condições para a promoção, proteção e recuperação da saúde, a organização e o funcionamento dos serviços correspondentes e dá outras providências. Brasília: Diário Oficial da União, 1990.

BRESSER-PEREIRA, Luiz C. A Reforma do Estado dos anos 90: lógica e mecanismos de controle. Brasília: Cadernos Mare da Reforma do Estado, 1997.

BRUGUÉ, Quim. Modernizar la administración desde la izquierda: burocracia, nueva gestión pública y administración deliberativa. Revista del Clad Reforma y Democracia, n. 29, p. 1-16, 2004.

CARNEIRO, Ricardo; MENICUCCI, Telma M. G. Gestão pública no século XXI: as reformas pendentes. Brasília: Ipea, 2011.
CARVALHO, Elisabete. Decisão na administração pública: diálogo de racionalidades. Sociologia, Problemas e Práticas, n. 73, p. 131-148, 2013.

DUSSALT, Gilles. A gestão dos serviços públicos de saúde: características e exigências. Rev. Adm. Pública, Rio de Janeiro, v. 26, n. 2, p. 8-19, 1992.

ESCOREL, Sarah. História das políticas de saúde no Brasil de 1964 a 1990: do Golpe Militar à Reforma Sanitária. In: GIOVANELLA, Ligia et al. (Org.). Políticas e sistema de saúde no Brasil. Rio de Janeiro: Fiocruz, 2012. p. 323-363.

FALAVIGNA, Asdrubal et al. Avaliação das publicações de cirurgiões de coluna brasileiros na última década. Coluna/Columna, v. 11, n. 4, p. 294297, 2012.

FLEURY, Sonia. Reforma sanitária brasileira: dilemas entre o instituinte e o instituído. Ciência \& Saúde Coletiva, v. 14, n. 3, p. 743-752, 2009.

FREY, Klaus. Governança urbana e participação pública. RAC-Eletrônica, v. 1, n. 1, p. 136-150, 2007.

HOCHMAN, Gilberto; ARRETCHE, Marta; MARQUES, Eduardo (Org.). Políticas públicas no Brasil. Rio de Janeiro: Fiocruz, 2008.

KLERING, Luis R.; PORSSE, Melody de C. S.; GUADAGNIN, Luis A. Novos caminhos da administração pública brasileira. Análise, v. 21, n. 1, p. 4-17, 2010.

LIMA, Gabriela F. M.; PAPI, Luciana P. Abordagem sobre a modernização administrativa: há uma alternativa ao gerencialismo?. In: CONGRESSO DE GESTÃO PÚBLICA, 8., 2015. Anais eletrônicos... Brasília: Consad, 2015. Disponível em: <www. consad.org.br>. Acesso em: 8 maio 2015.

MARQUES, Eduardo; FARIA, Carlos A. P. de (Org.). A política pública como campo multidisciplinar. São Paulo: Unesp; Rio de Janeiro: Fiocruz, 2013.

MARTELLI JUNIOR, Hercílio et al. Pesquisadores do CNPq na área de medicina: comparação das áreas de atuação. Revista da Associação Médica Brasileira, v. 56, n. 1, p. 478-483, 2010.

MATIAS PEREIRA, José. A governança corporativa aplicada no setor público brasileiro. Administração Pública e Gestão Social, v. 2, n. 1, p. 109-134, 2010. 
MENDES, Eugênio V. 25 anos do Sistema Único de Saúde: resultados e desafios. Estud. Av., v. 27, n. 78, p. 27-34, 2013.

PAIM, Jairnilson et al. The Brazilian health system: history, advances, and challenges. Lancet, v. 377, n. 9779, p. 1778-1797, 2011.

PAIM, Jairnilson. A Constituição Cidadã e os 25 anos do Sistema Único de Saúde (SUS). Cadernos de Saúde Pública, v. 29, n. 10, p. 1927-1953, 2013.

PERSSON, Olle; DANELL, Rickard; SCHNEIDER, Jesper. How to use Bibexcel for various types of bibliometric analysis. In: ASTRÖM, Fredrik et al. Celebrating scholarly communication studies: a festschrift for Olle Persson at his 60th birthday. Lund: Issi, 2009. p. 9-24.

PETERS, B. Guy. Os dois futuros do ato de governar: processos de descentralização e recentralização no ato de governar. Revista do Serviço Público, v. 59, n. 3, p. 289-307, 2008.

POLLITT, Christopher. Envisioning public administration as a scholarly field in 2020. Public Administration Review, n. esp., p. 292-294, dez. 2010 .

RUAS, Terry L.; PEREIRA, Luciana. Como construir indicadores de ciência, tecnologia e inovação usando Web of Science, Derwent World Patent Index, Bibexcel e Pajek?. Perspectivas em Ciência da Informação, v. 19, n. 3, p. 52-81, 2014.

SANTOS, Lenir. Sistema Único de Saúde - os desafios da gestão interfederativa. Campinas: Saberes Editora, 2013a.

SANTOS, Nelson R. SUS, política pública de Estado: seu desenvolvimento instituído e instituinte e a busca de saídas. Ciência e Saúde Coletiva, v. 18, n. 1, p. 273-280, 2013b.

SCIELO. Critérios, política e procedimentos para a admissão e a permanência de periódicos científicos na Coleção SciELO Brasil. São Paulo, 2014. Disponível em: $<$ www.scielo.br/avaliacao/20141003NovosCriterios_ SciELO_Brasil.pdf $>$. Acesso em: 22 set. 2015.

SCOTT, John. Social network analysis: a handbook. 2. ed. Londres: Sage, 2000.
SECCHI, Leonardo. Modelos organizacionais e reformas da administração pública. Rev. Adm. Pública, Rio de Janeiro, v. 43, n. 2, p. 347-369, 2009.

SOARES, Ana L. A. G. Análise de redes sociais no estudo do uso de drogas: uma revisão sistemática. Rio de Janeiro: UFRJ, 2012.

SOUZA, Celina. Políticas públicas: uma revisão da literatura. Sociologias, v. 8, n. 16, p. 20-45, 2006.

SOUZA, Queila; QUANDT, Carlos. Metodologia de análise de redes sociais. In: DUARTE, Fabio; QUANDT, Carlos; SOUZA, Queila (Org.). O tempo das redes. São Paulo: Perspectiva, 2008. p. 31-63.

TANAKA, Oswaldo Y.; TAMAKI, Edson M. O papel da avaliação para a tomada de decisão na gestão de serviços de saúde. Ciência da Informação, v. 17, n. 4 , p. 821-828, 2012.

TARRAGÓ, Daniel; BRUGUÉ, Quim; CARDOSO JÚNIOR, José C. A administração pública deliberativa: inteligência coletiva e inovação institucional a serviço do público. Rio de Janeiro: Ipea, 2015.

ULLRICH, Danielle R.; OLIVEIRA, Josiane S.; SCHEFFER, Angela B. B. Formação de redes sociais de coautoria na área de gestão de pessoas: uma análise bibliométrica em periódicos brasileiros no triênio 2007 a 2009. Rege - Revista de Gestão, v. 19, n. 4 , p. $553-570,2012$

VALMORE, Fabiane H. Relação produção-publicação da ciência política brasileira: uma análise a partir dos editores de sete periódicos nacionais. In: SEMINÁRIO INTERNACIONAL DE CIÊNCIA POLÍTICA ESTADO E DEMOCRACIA EM MUDANÇA NO SÉCULO XXI, 1., 2015. Anais... Porto Alegre: UFRGS, 2015. Disponível em: <www.ufrgs.br/sicp/ files/2015/09/2.-VALMORE-Fabiane-Helene-RelaçãoProdução-publicação-da-Ciência-Política-BrasileiraUma-Análise-a-partir-dos-Editores-de-Sete-Periódicos-Nacionais.pdf>. Acesso em: 22 set. 2015.

VANZ, Samile A. de S. Redes colaborativas nos estudos métricos de ciência e tecnologia. Liinc em Revista, v. 9, n. 1, p. 171-180, 2013.

VIANA, Ana L. D.; LIMA, Luciana D.; OLIVEIRA, Roberta G. Descentralização e federalismo: a política de saúde em novo contexto - lições do caso brasileiro. Ciência \& Saúde Coletiva, v. 7, n. 3, p. $493-507,2002$. 


\section{Ana Cristina Vidal Allegretti}

Doutora em odontologia - saúde coletiva, Secretaria Municipal da Saúde, Curitiba, PR, Brasil.

E-mail: crisallegre@hotmail.com.

\section{Simone Tetu Moysés}

$\mathrm{PhD}$ em epidemiologia e saúde pública, professora titular na Escola de Saúde e Biociências, Pontifícia Universidade Católica do Paraná, Curitiba, PR, Brasil. E-mail: simone.moyses@pucpr.br.

\section{Renata lani Werneck}

PhD em ciências da saúde, professora titular na Escola de Saúde e Biociências, Pontifícia Universidade Católica do Paraná, Curitiba, PR, Brasil. E-mail: renata.iani@pucpr.br.

\section{Carlos Olavo Quandt}

$\mathrm{PhD}$ em planejamento urbano e regional, professor titular na Escola de Negócios, Pontifícia Universidade Católica do Paraná, Curitiba, PR, Brasil. E-mail: carlos.quandt@pucpr.br.

\section{Samuel Jorge Moysés}

PhD em epidemiologia e saúde pública, professor titular na Escola de Saúde e Biociências, Pontifícia Universidade Católica do Paraná, Curitiba, PR, Brasil. E-mail: s.moyses@pucpr.br. 